\title{
Signs and Symptoms of Depression in Children and Adolescents with Type 1 Diabetes Mellitus: A Case Report
}

\author{
Herman \\ Department of Psychiatry, Medical Faculty, Udayana University, Sanglah General Hospital, Denpasar, Bali, \\ Indonesia \\ Corresponding author email: hermanpsikiatri2018@gmail.com
}

\section{Gusti Ayu I. Ardani}

Department of Psychiatry, Medical Faculty, Udayana University, Sanglah General Hospital, Denpasar, Bali, Indonesia

Luh Nyoman A. Aryani

Department of Psychiatry, Medical Faculty, Udayana University, Sanglah General Hospital, Denpasar, Bali, Indonesia

\section{Gusti Ayu T. Windiani \\ Department of Paediatrics, Medical Faculty, Udayana University, Sanglah General Hospital, Denpasar, Bali, Indonesia}

\author{
I Gusti Ngurah S. Adnyana \\ Department of Paediatrics, Medical Faculty, Udayana University, Sanglah General Hospital, Denpasar, Bali, \\ Indonesia
}

\author{
Yunias Setiawati \\ Department of Psychiatry, Medical Faculty, Airlangga University, Dokter Soetomo Hospital, Surabaya, East Java, \\ Indonesia
}

\begin{abstract}
Depression is a fundamental disorder characterized by changes in mood or affect toward depression with or without anxiety. Depression is a state of mental disorder characterized by three main symptoms and seven additional symptoms. Diabetes Mellitus Type-1 (T1DM) is a systemic disorder caused by impaired glucose metabolism, which is characterized by chronic hyperglycemia. Depression is common in patients with T1DM. In this case report, a 13-year-old girl was consulted because she looks sad. A feeling of sadness has been felt for 3 months and has been getting worse since a week ago, which was initially because of T1DM. Patients usually work at home and carry out daily activities as usual. Currently, the patient has no desire and gets tired easily, especially when doing usual activities, thinking the pain will get worse and thinking that she can't recover. Complaints are felt throughout the day and worsen at night, especially before bed or when alone. The patient feels that she is useless and his future is bleak. During pregnancy, the patient's mother routinely checks with the midwife and gets complete immunizations. The patient was born vaginally and cried spontaneously. The patient also received complete basic immunization.
\end{abstract}

Keywords---case report, children, cognitive behavioral therapy, depression, diabetes mellitus 


\section{Introduction}

Depression is a fundamental disorder characterized by changes in mood or affect toward depression with or without anxiety. Depressive disorders in children and adolescents are often not detected or treated. Early-onset of depressive disorder in children and adolescents is often behavioral and physical complaints, which obscure the symptoms of depression as seen in adults. Complaints of depression in children and adolescents can appear such as irritable or cranky mood, chronic boredom, or loss of interest in pleasurable entertainment activities. Patients can also withdraw from social environments such as not wanting to hang out with friends and avoiding school, which can lead to decreased academic achievement. Other problems such as changes in sleep-wake patterns, frequent complaints of unexplained physical pain, behavioral problems, and drug abuse can occur as a result of depression.

The World Health Organization (WHO) states that the prevalence of depression can vary by age, with the highest reported in older adults ( $>7.5 \%$ in women aged 55-74 years and $>5.5 \%$ in men). Data from Riskesdas in 2018 stated that the prevalence of depression in the population aged 15 years in Indonesia was $6.1 \%$. The incidence of depression in children has also been reported to occur in patients with Type I Diabetes Mellitus (T1DM). Pharmacological and non-pharmacological management can be given in this condition (World Health Organization, 2017). Treatment also depends on the degree of depression, such as mild, moderate, and severe.

Antidepressant drugs can be used as an initial treatment modality for patients with mild, moderate, or severe depressive episodes. Based on Mojtabai \& Olfson (2008), second-generation antidepressants, such as SSRIs and SSNRIs are the most commonly used pharmacological agents in the treatment of acute major depressive disorders (MDD) (Gartlehner et al., 2017). The choice of pharmacological treatment as a modality for treating depression is based on a history of clinical symptoms that respond positively to antidepressant therapy, moderate to severe depression, sleep disturbances or significant loss of appetite, agitation, patient preferences, and the anticipated need for maintenance therapy (American Psychiatric Association, 2000).

Cognitive-behavioral therapy (CBT) is part of one of the non-pharmacological therapies that can be used as a therapeutic approach for depression in children. The CBT model proposes that cognition can mediate the relationship between situations and behavioral, emotional, and physiological reactions. Therefore, the goal of CBT-based therapy is to establish the relationship between cognition and behavior so that it is clear to the individual and that the individual becomes aware. Thus, the individual can improve maladaptive thinking patterns. Management of T1DM includes insulin administration, diet management, exercise, education, and self-monitoring. Insulin administration aims to ensure that insulin levels are sufficient in the body for 24 hours to meet metabolic needs, either given as basal insulin or corrected insulin with higher levels (bolus) due to the glycemic effect of food (Yati \& AAP, 2017).

\section{Case report}

The patient is a 13-year-old girl, Hindu, Balinese. Currently in the second grade of junior high school, unmarried, and a student. The patient was referred to the psychiatry department with complaints of sadness. Patients experience changes in behavior after complaining of current pain (Rodin et al., 2002; Kakleas et al., 2009). The patient becomes quiet and rarely socializes. The patient's consciousness is still clear and there is no difficulty in speaking. The patient felt sad which had started 3 months ago and worsened in the last 2 weeks when she visited the hospital. The patient becomes sad accompanied by feelings of fatigue and a gloomy outlook on the future. The patient is worried that the pain will not heal. The patient also experienced sleep disturbances due to thinking about the pain accompanied by decreased appetite (Laraeni et al., 2021; Mustika et al., 2016).

The patient was diagnosed with T1DM in January 2019. The patient was treated at Sanglah Hospital in March 2020. Initial complaints were nausea, vomiting, diarrhea once, accompanied by headaches. Furthermore, the results of blood tests showed an increase in blood sugar. The patient appears to experience behavioral changes such as being alone and seems sad since the illness. Therefore, the patient was consulted by a pediatrician to a psychiatrist specialist at the Mental Polyclinic of the State University Hospital on October 23, 2021. After taking a psychiatric examination, the patient received 10 milligrams of fluoxetine therapy every 24 hours intraorally, taken every night. According to his mother, the patient was born normal and experienced normal growth and development. The patient was said to have never missed a grade at school. The patient is the 3rd child of four siblings. The patient is a closed child and when there is a problem, the patient is more likely to keep the problem by herself. Sometimes, the patient is difficult to manage when ordered by his mother (Rechenberg \& Koerner, 2021; de Groot et al., 1999).

On physical examination, physical status was found within normal limits, nutritional status was good, and general status was within normal limits. Examination of the psychiatric status found a reasonable appearance, adequate visual contact, clear consciousness, and mood/effect is sad/depressive. The thinking process is logical, realistic, 
coherent, and there are no strange ideas. Then, there is no perception of hallucinations and illusions. There is a history of mixed-type insomnia. The mechanism of self-defense is repression. Then, from the generalist status examination, no abnormalities were found. PK laboratory results (12/11/2021: HbA1C 13.8\%).

The diagnosis of this patient according to the Pedoman Klasifikasi dan Diagnosis Gangguan Jiwa Indonesia III (PPDGJ-III) on Axis I was Moderate Depressive Episode Without Somatic Symptoms (F32.10). On Axis II was cheerful and sociable, ego defense mechanism was repression. On-Axis III is T1DM with a history of moderate diabetic ketoacidosis. Axis IV problems with the disease and on Axis V, GAF score at examination 60-51 and GAF for the last 1 year. The patient was given pharmacological therapy with 10 milligrams of Fluoxetine every 24 hours intraorally (morning), while the non-pharmacological therapy given was supportive psychotherapy and cognitive behavioral therapy. Based on pediatric therapy, Novorapid injection 8-15-8 units, Levemir injection 14 units, and metformin 500 milligrams every 12 hours intraorally were given. The family is also given psychoeducation by a psychiatrist (d'Annunzio et al., 2020; Valerio et al., 2007).

\section{Discussion}

The patient is a female, 13 years old, weight $21 \mathrm{~kg}$, height $146 \mathrm{~cm}$, Hindu, Balinese, junior high school in Ubud Bali. The patient was referred to the psychiatry department with complaints of sadness. Patients experience changes in behavior after experiencing this illness. The patient becomes quiet and rarely socializes, but the consciousness remains clear, and does not have difficulty speaking. The patient's sadness began for the first time since 3 months ago and worsened in the last 2 weeks when she visited the hospital. Patients experience changes in feelings to be sad and easily tired. Patients also worry that the future is bleak and the pain will not heal. Sleep disturbances are also happening due to thinking about their illness and a decrease in appetite (Kakleas et al., 2010; Zuo et al., 2020). The results of the Hba1C blood test showed an increase in blood glucose. History of diagnosis of type 1 diabetes mellitus since January 2019. This case according to PPDGJ III and DSM V was diagnosed as a moderate depressive episode without Somatic symptoms (F32.10). In this case, the patient experienced behavioral changes that looked sad and tired easily. The patient also felt that she had no hope of recovering from his current illness and had a desire to commit suicide because of desperation, but the patient did not attempt suicide. The patient had sleep disturbances and decreased appetite. This causes the patient to be given pharmacological and non-pharmacological therapy. The patient was given pharmacological therapy with 10 milligrams of Fluoxetine, every 24 hours, orally (morning). Meanwhile, the non-pharmacological therapy provided is supportive psychotherapy and cognitive psychotherapy. The patient's family was also given psychoeducation (Riquetto et al., 2015; Babatzia et al., 2020).

\section{Conclusion}

Based on the psychodynamic analysis, there were several biologic factors found in this patient, such as the presence of unstable blood sugar with a diagnosis of T1DM. This biological factor makes the patient feel sad and causes maladaptive thoughts. From a psychological point of view, the patient feels that her parents are different. She needs attention to the affection from her parents and the nuclear family. From a social perspective, the patient began to feel uncomfortable when playing with her friends. She was worried that she would not be able to chat and play with her friends again. In this case report, it can be concluded that moderate depressive episodes with T1DM in children need to be treated appropriately (Ruiz, 2000; Riskesdas, 2018). Treatment should consist of pharmacological and nonpharmacological therapy.

\section{Acknowledgment}

We would like to thank all parties who have participated in this case report. Specifically, we would like to thank Sanglah General Hospital for providing and allowing us to report this case.

\section{Declaration}

Funding: None

Conflict of interest: There is no other party's interest.

Ethical approval: Not required

\section{References}

American Psychiatric Association. (2000). Practice guideline for the treatment of patients with major depressive disorder (revision). Am J Psychiatry, 157, 1-45. 
Babatzia, A., Papaioannou, W., Stavropoulou, A., Pandis, N., Kanaka-Gantenbein, C., Papagiannoulis, L., \& Gizani, S. (2020). Clinical and microbial oral health status in children and adolescents with type 1 diabetes mellitus. International dental journal, 70(2), 136-144. https://doi.org/10.1111/idj.12530

d'Annunzio, G., Maffeis, C., Cherubini, V., Rabbone, I., Scaramuzza, A., Schiaffini, R., ... \& Maghnie, M. (2020). Caring for children and adolescents with type 1 diabetes mellitus: Italian Society for Pediatric Endocrinology and Diabetology (ISPED) statements during COVID-19 pandemia. diabetes research and clinical practice, 168, 108372. https://doi.org/10.1016/j.diabres.2020.108372

de Groot, M., Jacobson, A. M., Samson, J. A., \& Welch, G. (1999). Glycemic control and major depression in patients with type 1 and type 2 diabetes mellitus. Journal of psychosomatic research, 46(5), 425-435. https://doi.org/10.1016/S0022-3999(99)00014-8

Gartlehner, G., Wagner, G., Matyas, N., Titscher, V., Greimel, J., Lux, L., ... \& Lohr, K. N. (2017). Pharmacological and non-pharmacological treatments for major depressive disorder: review of systematic reviews. BMJ open, 7(6), e014912.

Kakleas, K., Kandyla, B., Karayianni, C., \& Karavanaki, K. (2009). Psychosocial problems in adolescents with type 1 diabetes mellitus. Diabetes \& metabolism, 35(5), 339-350. https://doi.org/10.1016/j.diabet.2009.05.002

Kakleas, K., Karayianni, C., Critselis, E., Papathanasiou, A., Petrou, V., Fotinou, A., \& Karavanaki, K. (2010). The prevalence and risk factors for coeliac disease among children and adolescents with type 1 diabetes mellitus. Diabetes research and clinical practice, 90(2), 202-208. https://doi.org/10.1016/j.diabres.2010.08.005

Laraeni, Y., Danuyanti, I. G. A. N., Resnhaleksmana, E., Pauzi, I., Mataram, I. K. A., \& Agustini, N. P. (2021). High antioxidant level in cajanus sajan reduces blood glucose level and improves blood lipid profile of rats as diabetes mellitus models. International Journal of Health Sciences, 5(1), 29-37. https://doi.org/10.29332/ijhs.v5n1.725

Mojtabai, R., \& Olfson, M. (2008). National patterns in antidepressant treatment by psychiatrists and general medical providers: results from the national comorbidity survey replication. The Journal of clinical psychiatry, 69(7), 12444.

Mustika, I. W., Candra, I. W., \& SC, N. Y. (2016). The relationship between the level of spiritual and self-esteem on depression towards patients with diabetes mellitus. International Research Journal of Engineering, IT \& Scientific Research, 2(7), 125-133. Retrieved from https://sloap.org/journals/index.php/irjeis/article/view/507

Rechenberg, K., \& Koerner, R. (2021). Cognitive behavioral therapy in adolescents with type 1 diabetes: An integrative review. Journal of Pediatric Nursing, 60, 190-197. https://doi.org/10.1016/j.pedn.2021.06.019

Riquetto, A. D. C., de Noronha, R. M., Matsuo, E. M., Ishida, E. J., Vaidergorn, R. E., Soares Filho, M. D., \& Calliari, L. E. P. (2015). Thyroid function and autoimmunity in children and adolescents with Type 1 Diabetes Mellitus. Diabetes research and clinical practice, 110(1), e9-e11. https://doi.org/10.1016/j.diabres.2015.07.003

Riskesdas, L. N. (2018). Kementerian Kesehatan RI Badan Penelitian dan Pengembangan Hasil Utama Riset Kesehatan Dasar. Kementerian Kesehatan Republik Indonesia; Ministry of Health Republc of Indonesia: Jakarta, Indonesia, 1-100.

Rodin, G., Olmsted, M. P., Rydall, A. C., Maharaj, S. I., Colton, P. A., Jones, J. M., ... \& Daneman, D. (2002). Eating disorders in young women with type 1 diabetes mellitus. Journal of psychosomatic research, 53(4), 943949. https://doi.org/10.1016/S0022-3999(02)00305-7

Ruiz, P. (2000). Comprehensive textbook of psychiatry (Vol. 1, pp. 938-950). B. J. Sadock, \& V. A. Sadock (Eds.). Philadelphia: lippincott Williams \& wilkins.

Valerio, G., Spagnuolo, M. I., Lombardi, F., Spadaro, R., Siano, M., \& Franzese, A. (2007). Physical activity and sports participation in children and adolescents with type 1 diabetes mellitus. Nutrition, metabolism and cardiovascular diseases, 17(5), 376-382. https://doi.org/10.1016/j.numecd.2005.10.012

World Health Organization. (2017). Depression and other common mental disorders: global health estimates (No. WHO/MSD/MER/2017.2). World Health Organization.

Yati, N. P., \& AAP, B. T. (2017). Diagnosis dan Tata Laksana Diabetes Melitus Tipe-1 pada Anak dan Remaja. Ikatan Dokter Anak Indonesia.

Zuo, X., Dong, Z., Zhang, P., Zhang, P., Chang, G., Xiang, Q., .. \& Lou, P. (2020). Effects of cognitive behavioral therapy on sleep disturbances and quality of life among adults with type 2 diabetes mellitus: A randomized controlled trial. Nutrition, Metabolism and Cardiovascular Diseases, 30(11), 1980-1988. https://doi.org/10.1016/j.numecd.2020.06.024 